\section{The effect of citrate preservatives on estimating the Westergren method of erythrocyte sedimentation rates}

\author{
H. STERNDALE From the Department of \\ Pathology, General Hospital, Margate
}

For the past two years, disposable containers for use in erythrocyte sedimentation rate (E.S.R.) estimations have been made available ${ }^{1}$. These are of clear plastic fitted with a plastic lid and each contains $0.5 \mathrm{ml}$. of $3.8 \%$ sodium citrate solution with added preservatives to prevent moulds forming.

The preservatives used are a mixture of $0.2 \mathrm{~g}$. of propyl hydroxybenzoate and $1.5 \mathrm{~g}$. of methyl hydroxybenzoate in every litre of citrate solution. Because there appeared to be an unduly high proportion of low sedimentation rates and a large percentage of ' $1 \mathrm{~mm}$. fall in the first hour' a series of estimations was carried out to determine the cause of inhibition.

A large number of unused, dry containers of the type normally supplied as E.S.R. bottles were required and also a quantity of the sodium citrate solution containing the preservatives. In addition, a number of plain glass tubes, $7 \frac{1}{2} \times 1 \mathrm{~cm}$., were carefully cleaned and dried and a quantity of $3.8 \%$ sodium citrate solution was prepared containing no preservative.

Blood was collected from 25 random cases in four ways in the ratio of $0.5 \mathrm{ml}$. sodium citrate solution and $1.5 \mathrm{ml}$. of blood and distributed as follows:-

A Into a glass tube containing citrate solution without preservative.

B Into a glass tube containing citrate solution with preservative.

C Into a plastic container containing citrate solution without preservative.

D Into a plastic container containing citrate solution with preservative.

The blood samples were then mixed carefully an equal number of times and immediately set up using Westergren pipettes.

Readings were taken after one hour in all 25 cases, in

'Stayne Laboratories Ltd.

Received for publication 10 April 1963
20 cases after two hours, in nine cases after three hours, and in 11 cases after four hours.

Five cases labelled as anaemia showed a retardation of fall varying from $13 \mathrm{~mm}$. maximum up to $1 \mathrm{~mm}$. minimum in the first hour with an average fall of $5.4 \mathrm{~mm}$. and with a corresponding retardation in the second, third, and fourth hour readings.

Five cases of pregnancy showed a retardation ranging from 8 to $2 \mathrm{~mm}$. with an average of $4.3 \mathrm{~mm}$. in the first hour and $7 \mathrm{~mm}$. in the fourth hour readings.

Of the remaining 15 cases, 12 showed a wide variation on retardation from $21 \mathrm{~mm}$. to only $1 \mathrm{~mm}$. and in three cases there was actually a slight reversal of the ratio, for which no explanation can be offered.

In 21 of the tests, there was a recordable difference between the sedimentation of the red cells using the citrate solution with and without preservatives. The variation was not constant, in some cases amounting to only a few millimetres, but in other cases to a larger difference.

The retardation of the fall of erythrocytes was accentuated in readings at the second, third, and fourth hours and with one exception, those cases with a raised E.S.R. showed the greatest inhibitory effect.

In the majority of cases, the use of the disposable containers produced a slight inhibitory effect as compared with the use of glass tubes, irrespective of the type of citrate solution, and the possibility that this is due to a variation in $p \mathrm{H}$ is being investigated.

Retardation of the fall of erythrocytes is well known in such conditions as polycythaemia and congestive heart failure owing to an increase in blood viscosity. Retardation has also been reported after corticosteroid therapy (Fearnley and Bunim, 1951) and with dry anticoagulants such as are used in the Wintrobe method (Duxbury, 1957).

It is suggested that the inhibitory effect experienced in the estimations now recorded is the direct result of including preservatives in the sodium citrate solution.

Since these facts were made known to them, the manufacturers, have withdrawn the E.S.R. container with preservative solution, replacing it by bottles containing simple sodium citrate solution.

I am grateful to Stayne Laboratories Ltd., for their cooperation and making available the materials. My thanks are due to Mr. J. R. Belsey for technical assistance.

\section{REFERENCES}

Duxbury, McD. (1957). Lancet, 1, 734.

Fearnley, G. R., and Bunim, J. J., (1951). Ibid., 2, 1113. 